blood-cast, and afterwards to check the hæmorrhage, and relieve the congestion of the uterus. With this view, ergot in full and repeated doses should be given along with ipecacuanha, sedative solution of opium, or belladonna. Should there be great irritability of the stomach, a hypodermic solution of ergotin and morphia, or atropia, may be used instead. After the expulsion of the clot, ergot in small doses should be continued for some time, and combined with belladonna or cannabis indica and cinnamon, or the tincture of acteæ racemosa instead of the ergot, if the constitution of the patient is rheumatic. The ergot checks the hæmorrhage by exciting uterine contractions; but it lessens it also by its constringent effect on the capillaries, and thus tends to relieve the uterine congestion.

It is not always an easy matter to effect the cure of a highly congested uterus ; this is partly owing to its position and partly to the peculiarity of its blood-supply. Some authorities recommend, in such cases, scarification of the os or the application of leeches to it. This plan of treatment does not seem to me at all rational. It is surely better to endeavour to determine the flow of blood from than to a congested organ. In active hyperæmia of the brain, or inflammation of its coverings, leeches are applied with effect behind the ears, or the cupping glasses to the nape of the neck or between the shoulders. On the same principle I think leeches should be applied to the labia, above the pubes, or over the insertion of the broad ligament of the uterus, as advised by Dr. J. Whitehead and others, or over the ovarian region or the sacrum, if these parts are the seat of pain.

Should there be great fulness of the hæmorrhoidal vessels or hepatic congestion, much advantage will be obtained by leeching round the anus. The extent of the hæmorrhage does not contra-indicate further depletion by means o leeches or cupping. Their judicious employment will be found of great service, along with appropriate remedies, both in checking the hæmorrhage and in restoring the congested uterus to its normal condition. Plugging the vagina will hardly ever be needed in these cases.

It may be necessary to give along with ergot, or without it, tannin, gallic acid, one or other of the mineral acids, or some astrivgent preparation of iron - the perchloride, pernitrate, tincture or sulphate with or without salines, combined according to the exigencies of the case or the predilections of the practitioner. With the internal exhibition of medicine, the frequent use of astringent and sedative injections per vaginam should be had recourse to. The shin and state of the kidneys demand attention, and the bowels must be kept open, as constipation tends to produce and maintain uterine congestion. For the hypogastric pain nothing answers better than either the compound chloroform and aconite liniment, or mercury ointment with extract of belladonna, applied over the affected part.

The patient ought to be kept in the horizontal position, and during the day to recline on a couch so soon as her condition will admit of her safe removal from bed. A regulated diet should be enforced, and all strong wines and spirits prohibited, unless there is great exhaustion, when small quantities of them may be cautiously given. In some ex. treme cases, where there is danger of fatal collapse setting in, a large quantity of these stimulants may be absolutely needed. But in the ordinary hrmorrhage from any form of congestion of the uterus my experience is that they are not required, and, if riven, do harm by keeping up the hyperæmic state of the uterus. Instead of the heavy wines and spirits, Bordeaux or similar light wines may be allowed; they assist digestion and are refreshing, tonic, and slightly astringent.

By the employment of the means already indicated convalescence will be gradually established; and afterwards, by the proper use of alteratives and tonics (mineral and vegetable, both nervine and general), the cure will be effected and the general heal th re-established, which may be hastened by change of air and a course of chalybeate or other mineral waters. Blackburn

CHILDRFy's Hospital, Bristol. - The annual meeting of this charity was held on the 19 th inst. The report stated that of the 399 little patients admitted during the past year, 212 were restored to their friends cured, 128 were benefited, and 11 died. A new site for the hospital has been secured, and the committee are waiting hopefully for the funds necessary to enable them to construct a suitable building thereon.
OBSERVATIONS ON CASES OF

PNEUMONIA TREATED IN THE DIVISIONAL FIELD HOSPITAL, CABUL, 1879-80.

BY J. MORRIS, M.D.,

SURGEON, ARMY MEDICAL DEPARTMENT.

DURING the late campaign in Afghanistan thirty-five cases of pneumonia were under my care at Cabul, all of which belonged to a single Highland regiment. Disease in the greater number of cases was induced by overwork, combined with exposure to severe cold and want of sleep. A large proportion of cases was admitted during the first five days of January, 1880, partly due to reaction after the excitement of the siege. Several of the cases must have contracted the disease on New Year's eve, which is a great festival in Highland regiments. The barrack-rooms in Sherpur were very cold, being $60 \mathrm{ft}$. by $16 \mathrm{ft}$.; a small fire at each end had very little effect on the general temperature of the room. The floors were constantly damp, water being found about three feet from the surface. There was no attempt at ventilation. In eighteen cases the right lung was affected; in ten, the left; the remaining seven had both lungs implicated. Mortality, eleven, or 31.4 per cent. Double pneumonia, four fatal out of seven, or $57 \cdot 14$ per cent. Average duration of cases, eight to ten days before convalescence set in ; average duration of fatal cases, $5 \cdot 1$ days. In many cases the disease was complicated with pleurisy, in one with remittent fever, and in thiee symptoms of meningeal inflammation were present for some time before death. Where death took place, it was usually the result of apnoea, the patients presenting the bluish appearance characteristic of non-aeration of blood. The disease was generally of the catarrhal or diffuse character. In four cases, where a single lobe only was affected, resolution occurred on the third or fourth day. In the earliest stage the treatment was tartrate of antimony in doses of a quarter of a grain every three hours, accompanied by large doses of potash, to render the sputa less viscid. As soon as the sputa could be brought up easily, carbonate of ammonia was substituted for the alkaline mixture, the antimony being still continued. As the disease was in the majority of cases of an extremely asthenic type, stimulants were exhibited at an early stage, gradually increased as needed. Sinapisms were applied daily over the lung affected. When dyspncea became excessive, dry cupping over the front of the chest usually gave great relief.

I may remark, in conclusion, that the patients in the Divisional Hospital were supplied with every comfort in the way of food, wine, \&c. The excessive severity of the weather was a large factor in causing the high rate of mortality. The thermometer frequently marked $28^{\circ}$ to $30^{\circ}$ of frost. I have seen it mark $20^{\circ} \mathrm{F}$. for several successive days at $10 \mathrm{~A}$.M. It can therefore be easily understood how impossible it was to keep up an equable temperature in wards hastily fitted up, with doors and windows fitting imperfectly, and little or no drainage.

\section{SYMPTOMS OF CANTHARIDES POISONING DURING ITS INTERNAL ADMINISTRATION.}

By T. F. CLARKE, M.R.C.S. ENG., \&c.

THE two following cases, exhibiting symptoms of poisoning by cantharides during the later treatment of gonorrhœe, may be of interest on account of the favourable result in each case.

I may preface my remarks by stating that in nearly every case of gonorrhoea for the primary symptoms-e.g., scalding, chordee, \&c., with thick discharge,-I prescribe saline medicines and tepid-water injections. When the discharge becomes thinner, and all active inflammation has abated, I prescribe iron and cantharides internally (tincture of the perchloride of iron and tincture of cantharides, of each five minims, three times a day), and an injection of sulphate of zinc (two grains to the ounce). Such was the course followed in the present instances.

In the first case my patient had been taking the cantha- 
rides mixture for five days, at the end of which time he was virtually cured. A week after the discontinuance of the medicine I was summoned to him for violent pain over the bladder, and this was accompanied on the following day with strangury. These symptoms, at first very severe, passed off at the end of about four days, during which time I gave him nitric ether and hyoscyamus internally, and ordered hot baths whenever the strangury came on.

In the second case the patient, after taking two doses only of the cantharides mixture, had some of the symptoms of poisoning-viz., frequent desire to pass urine, burning pain during micturition, which was very difficult, and always accompanied towards the end of the process by a few drops of blood. I ordered him to take only half the dose, but these directions were not followed, and he continued with the full dose, the symptoms, nevertheless, rapidly abating.

In each case every trace of the gonorrhoea was removed, and as soon as the active symptoms produced by the cantharides passed off, the patient felt as well as ever, and had not the slightest discomfort in the urinary organs. Why these symptoms of cantharides poisoning should have presented themselves-for I frequently administer the drug in much larger doses, and without any untoward symptom-I am at a loss to understand. The delay of the symptoms in the second case may, I think, be explained by the supposition that the drug became stored up in the kidneys, and that after a short time its cumulative action gave rise to the poisoning symptoms.

Somerset East, Cape Colony.

\section{a ditirtor}

\section{HOSPITAL PRACTICE,}

\section{BRITISH AND FOREIGN.}

Nulla autem est alia pro certo noscendi via, nisi quamplurimas et morborun et dissectionum historias, tum aliorum tum proprias collectas habere, et inter ge comparare.-Noredan De Sed. et Caus. Morb., Lib. ir. Procemium.

\section{WESTMINSTER HOSPITAL.}

ANEURISM OF ASCENDING AORTA OPENING INTO A FALSE ANEURISM BETWEEN THE ASCENDING AORTA AND STERNUM ; APPARENT IMPROVEMENT UNDER LARGE DOSES OF IODIDE OF POTASSIUM; DEATH.

(Under the care of Dr. STURGES.)

For the notes of the following case we are indebted to Dr. W. Gristock, medical registrar.

E. D-, aged fifty-five, a stableman, was admitted on Sept. 28th, 1880. He had previously drunk a good deal of rum; had rheumatism once several years before; no history of syphilis; had been much exposed to the weather, and had often had insufficient nourishment. He was in the hospital first in May, 1877, with evident aneurism of the aorta, with distinct pulsating bulging in the second right intercostal space. Though he had since then been in different hospitals over and over again, he had been able to do a little light work at times. The last time he was in Westminster Hospital was in 1878. The signs of aneurism were most marked, but under large doses of iodide of potassium and rest, both the symptoms and physical signs subsided very considerably, the tumour becoming apparently solid. During the summer of 1880 he did light work and lived badly. He caught cold a month before admission, and became much worse. He had much aching pain in the right axilla and down the right arm, and his hand felt numb. He had also some pain and numbness in the left arm, which was never previously affected. He had occasional dysphagia for liquids, some dyspnoea-_." a choking sensation." During the week before admission pain in the back came on. The appetite was good, the bowels were rather constipated, but there was no sickness.

On admission there was orthopnœe, with especial difficulty in lying on the left side. There was slight working of the extraordinary inspiratory muscles, stridulous breathing and aneurismal cough. Pain was complained of in the back between the shoulder-blades, and there was dysphagia. The heart's apex beat was two inches and a half below, and an inch outside the nipple in the sixth space. There was visible and distinctly expansile pulsation to the right of the sternum reaching from the lower border of the second rib to the upper border of the fourth rib. Dulness extended from the first space to the fifth rib, reaching two inches and a half to the right of the sternum, and slightly across the sternum. The right margin of the sternum was tilted up There was no apex murmur, but a double murmur was heard over the tumour. There was a distinct thrill in both carotids ; no particular enlargement of the superficial veins of the chest was discernible, but the jugulars were prominent, especially the right, and the veins of the left arm were more prominent than those of the right. There was no pulsation in the back. Hollow respiratory sounds were audible over the root of the right lung, as if from pressure, and there were a few moist râles.

By Oct. 5th the patient was easier, and slept fairly well A fortnight later, after cold, foggy weather, the dyspucea had increased, and also the dysphagia, and the patient's sleep was very disturbed. The heart's impulse became very indistinct, probably by becoming covered by lung. on Oct. 16th the pulsation was distinct at two poists to the right of the sternum, as if there were two centres of pul sation. The pain in the back became more severe, and the patient also complained of pain in the right side of his throat, increased by swallowing. The bowels were also very contined; the pain was relieved by ice, though unaffected by fomentations. By the end of November the pain was much worse, not being so much relieved by ice. The dysphagia varied at different times, but there was a good deal of cough, which caused a "tearing pain." By the beginning of December there was acute pain in swallowing, with symptoms of pressure on the œsophagus. Orthopnea increased towards the end. The temperature, when taken, was about normal or subnormal throughout till Nov. 30th, when the patient had a rigor, after which the temperature was febrile : $102 \cdot 6^{\circ}$ on the evening of Nov. 30 th ; $100^{\circ}$ to $101^{\circ}$ afterwards; pulse 96 to 100 . The treatment consisted of iodide of potassium, in twenty grain doses, with bromide of potassium and chloroform, three times daily, from Oct. 13th to Nov. 5th, when it was omitted for a few days, then resumed. After Nov. 30th twenty grains of iodide of potas sium, simply in an ounce of water, were taken three times a day. Besides this, expectorant mixtures and sedatives were required, and frequent purgatives.

Necropsy (abstracted from the notes of Dr. HEBB, the pathologist) nineteen hours after death.-Body warm; rigor mortis well marked; an elastic tumour, about the size of a florin, in third right interspace, immediately adjacent to sternum; dulness on both sides in front from lower border of third rib downwards; the sac of the aneurism intimately adherent to sternum over an area of about two inches and a half in diameter; the veins at the root of the neck were much dilated and gorged with blood. The thoracic viscera were removed en masse. There were slight adhesions at left apex and anterior surface of right lung; lungs gorged with frothy serum, but otherwise normal. The pericardium was distended with clear yellow serous fluid. The heart was enlarged as a whole, mainly owing to dilatation of the right cavities, especially the auricle, but there was also slight hypertrophy of the left side. The right auricle was choked with whitish-yellow clot, and there was yellow clot in the other cavities. Aortic valves athoroma. tous, but competent; the other valves were normal, but the tricuspid orifice was dilated. Aorta atheromatous throughout, and ascending and transverse portions dilated enough to admit the closea fist. The dilated part bulged chiefly to the right. There was an opening abont the size of a shilling in the anterior wall of the ascending part. This opening communicated with a sac lying between the aorta and the sternum, and was adherent to the latter. The anterior and lateral portions of this sas were lined by laminated clot, the external part of which (about a quarter of an inch in thickness) was tough and evidently old. The more internal layers were softer. The posterior wall of the sac was formed by the aorta. It was smooth, yellow, and not covered by clot. The fourth dorsal vertebra was eroded, rough, and of purplish colour on its anterior aspect; and the sternum adjacent to the anterior sac was injected, purplish, swollen, and spongy. There were several dilatations of the abdominal aorta, the largest being just below the bifurcation on the right common iliac artery. There was another aneurism of the superior mesenteric artery, three inches in length and nearly one in dianeter. 